\title{
Desenvolvimento e educação. O planeamento estratégico integrado como fator de transformação societal de um território. $O$ caso do município da Lousã (Portugal)
}

\author{
Education and Development. Strategic planning as a factor of a territory's \\ societal transformation. The case of Lousã municipality (Portugal)
}

António Manuel Rochette Cordeiro, Rui Gama, Cristina Barros, Mafalda Frias

Universidade de Coimbra, Portugal

\section{Resumo}

\begin{abstract}
Num momento em que o papel das autarquias é cada vez mais relevante no domínio do planeamento estratégico territorial, tem-se como pano de fundo o trabalho que está a ser desenvolvido a este nível num dos municípios da região de Coimbra. Neste contexto, procura-se compreender a importância da componente educativa na estratégia definida no Plano Estratégico da Lousã, e como esta potenciou o desenvolvimento de um Projeto Educativo Local, assente nos princípios da democracia participativa e da cidadania ativa. Reconhecendo que as baixas qualificações da população residente são ainda um entrave ao desenvolvimento pessoal dos cidadãos e ao desenvolvimento de atividades produtivas mais intensivas em conhecimento e criatividade, perspetiva-se, no âmbito do Projeto Educativo Local, o desenvolvimento de políticas e projetos tendo como objetivos: promover o sucesso educativo; elevar os níveis de qualificação; potenciar a educação não formal e informal; aumentar a empregabilidade e promover uma cidadania ativa e qualificada. Com este artigo pretende-se, assim, discutir o processo de planeamento estratégico que está a ser desenvolvido num município de pequena dimensão (Lousã - Portugal), e como este pode ser catalisador de transformações em vários domínios. Em específico foi salientada a importância da componente Educação e como esta está a ser trabalhada a partir de um projeto específico - o Projeto Educativo Local. Apresentando uma abordagem inovadora, os resultados deste projeto deverão contribuir para a mobilização da sociedade com o objetivo de formar cidadãos mais conscientes e críticos da sua realidade local e global.
\end{abstract}

Palavras-chave: Planeamento estratégico. Plano estratégico da Educação. Projeto Educativo Local. Sucesso educativo.

AMRC é Professor, Doutor, e-mail: rochettecordeiro@fl.uc.pt

RG é Professor, Doutor, e-mail: rgama@fl.uc.pt

CB é Bolsista de Investigação Científica, Mestre, e-mail: cbarros@fl.uc.pt

MF é Bolsista de Investigação Científica, Mestre, e-mail: friasneves@uc.pt 


\section{Abstract}

During a time in which the role of municipalities concerning the territorial strategic planning is increasingly relevant, the main focus falls upon the work that is being developed in one of the Coimbra's region municipalities. In this context, it is necessary to understand the importance of the educational factor in the strategy defined in Lousã's Strategic Plan as well as its contribution to the development of a Local Educational Project, based on the principles of participatory democracy and active citizenship. Acknowledging that the resident's low qualifications still appear as an obstacle to the citizens' personal development and to the expansion of more intensive productive activities in terms of knowledge and creativity, it is perceived, within the scope of the Local Educational Project, the development of policies and projects which goals are: to promote educational success; to raise qualification levels; to intensify non-formal and informal education; to increase employability and to promote an active and qualified citizenship. This article intends to discuss the strategic planning process that is being developed in a small municipality (Lousã - Portugal), and how it can be a catalyst for transformations in several domains. In particular, the importance of the Education component was highlighted and how it is being worked out from a specific project - the Local Educational Project. Presenting an innovative approach, the results of this project should contribute to the mobilization of society with the objective of training citizens more aware and critical of their local and global reality.

Keywords: Strategic planning. Strategic plan for Education. Local Education Project. Educational success.

\section{Introdução}

Perante tempos de incertezas e alterações de contextos, o planeamento estratégico é um processo fundamental para se repensarem os lugares e definirem trajetórias exequíveis e resilientes de sucesso e de garantia de oportunidades e de qualidade de vida para os cidadãos que vivem os espaços geográficos.

É fundamental fazer a análise de conteúdo do espaço geográfico e identificar, de forma consequente, os condicionalismos, as vocações e as opções abertas em cada contexto, num balanço que se exige dinâmico entre o tradicional e o inovador. Sendo o planeamento estratégico também um sistema político de intervenção, contestam-se agora os modelos difusionistas e descendentes de intervenção, modelos que repetem ações e paradigmas em lugares que, sendo diferentes, requerem abordagens específicas.

No desenvolvimento do plano estratégico do município da Lousã e no âmbito do diagnóstico efetuado, foram identificados, entre outros, um conjunto de indicadores educativos que merecem alguma preocupação.

Desde logo, ficou sublinhado que a população residente na Lousã é relativamente menos escolarizada que a população portuguesa na sua globalidade e do que a população da "Região de Coimbra"1 ${ }^{1}$, apresentando elevados valores de população com baixos níveis de escolarização. Os dados relativos a 2011 indiciam que $8,9 \%$ da população residente com 15 ou mais anos de idade não tinha completado qualquer nível de ensino; cerca de $0,9 \%$ dos indivíduos entre os 6 e os 15 anos não estavam a frequentar o sistema de ensino e cerca de $24,8 \%$ dos jovens entre os 18 e os 24 anos deixaram de estudar sem completar o secundário. Relativamente à taxa de retenção e de desistência no ensino básico, no ano letivo de 2012/13, o valor de $11,3 \%$ revelou-se bastante acima da média da região, sendo que apenas os concelhos mais interiores e de montanha apresentam valores superiores. Já a taxa de conclusão/transição no ensino secundário, com $76,7 \%$, revela-se muito abaixo da média da região e do Continente.

No que diz respeito ao sucesso/insucesso escolar os resultados dos exames nacionais de 2014

\footnotetext{
1 Corresponde à Comunidade intermunicipal de Coimbra, unidade territorial portuguesa que integra os municípios de Arganil, Cantanhede, Coimbra, Condeixa-a-Nova, Figueira da Foz, Góis, Lousã, Mealhada, Mira, Miranda do Corvo, Montemor-o-Velho, Mortágua, Oliveira do Hospital, Pampilhosa da Serra, Penacova, Penela, Soure, Tábua, Vila Nova de Poiares, constituída ao abrigo da Lei no $75 / 2013$, de 12 de setembro.
} 
relativamente ao $4^{\circ}$ ano evidenciam uma média positiva $(54,1 \%)$, mas abaixo da média nacional e da região ( $2^{\circ}$ pior resultado). Nos exames de $12^{\circ}$ ano, a média concelhia negativa $(46,8 \%)$, faz com que a Lousã figure no grupo dos concelhos com resultados mais desfavoráveis.

Reconhecendo que há um longo caminho a percorrer no sentido da elevação das qualificações dos seus residentes, o município da Lousã definiu como uma das suas prioridades a Educação. De facto, um dos eixos estratégicos de desenvolvimento de maior relevância no Plano Estratégico diz respeito à "qualificação do potencial humano". Este eixo encontra-se a ser desenvolvido num autónomo projeto estratégico de educação: "Lousã, um Território Educativo — o Projeto Educativo Local".

Com o "Projeto Educativo Local" (PEL), desenhado e constituído numa lógica bottom-top, pretende-se criar políticas públicas locais de educação e formação, associando-as a determinadas opções de desenvolvimento. 0 projeto apela ao recurso a novas formas de gestão autárquica, consolidando práticas políticas comprometidas com a transformação diária da vida das pessoas e das diferentes comunidades, envolvendo-as e corresponsabilizando-as numa ação continuada. Um dos pontos fulcrais da nova visão para a educação passa pela criação, de forma concertada - agentes educativos, empresários, outros parceiros (movimento associativo, instituições sociais e de saúde, entre outros) —, de uma oferta diversificada e adaptada às necessidades do município em termos de ensino profissional e tecnológico, a implementação de um sistema de orientação vocacional que preveja e evite situações de insucesso e de abandono do percurso escolar e formativo por parte da população jovem.

É neste contexto que se procura discutir o Plano Estratégico de Educação no quadro do diagnóstico e da estratégia definida no Plano Estratégico. Sublinha-se a importância da dimensão educação na qualificação do território no quadro da especialização inteligente.

\section{O processo de planejameto estratégico territorial}

0 processo de planeamento estratégico representa uma forma fundamentada de definir prioridades e operacionalizar ações, permitindo otimizar as forças, mecanismos e recursos escassos da sociedade, evitando os desperdícios e a improvisação, sendo por isso fundamental para sistematizar e conferir racionalidade, direcionamento e interação lógica às ações, aumentando, desta forma, a sua eficácia, a sua eficiência e os seus impactos no território.

Num momento em que os fenómenos sociais, culturais, económicos e territoriais assumem grande complexidade, diversidade e mutações aceleradas, o planeamento estratégico apresentou-se como um novo paradigma de planeamento e gestão suscetível de fazer face aos problemas do desenvolvimento, nomeadamente no que se refere à escassez dos recursos e à mobilização dos agentes (Albrechts, 2006, 2010; Albrechts et al. 2003; Barros, 2011; Cremer-Schulte, 2014; Güell, 2000; Hall, 2014; Gonçalves \& Ferreira, 2015). Assim, além de visar conduzir a ação pública a longo prazo, atua a curto prazo, através de intervenções operacionais devidamente enquadradas por objetivos estratégicos. É por isso que, a esta integração de várias escalas e de vários horizontes temporais, alguns autores (Ferreira, 2005; Fonseca, 2006; Neves, 1996) designam a substituição do "planeamento estratégico" pela "gestão estratégica".

É certo que o desenvolvimento urbano já não pode ser controlado pelos instrumentos de planeamento territorial convencional (os planos físicos de ocupação e uso do solo), devido aos problemas decorrentes da recessão e do aumento do desemprego (e dos problemas relacionados com a instabilidade e a insegurança da reestruturação económica), como tal, os planos físicos estáticos perderam eficácia, uma vez que não resistem a ocorrências imprevistas (Healey, 2004; Faludi, 2010; Olesen \& Richardson, 2012). No entanto, apesar das diferenças entre ambos os tipos de planeamento, o planeamento estratégico visa ser complementar e não substituir o planeamento urbano tradicional (Hall \& Tewdwr-Jones, 2011; Knowles \& Rozenblat, 2016).

Deste modo, os planos e projetos estratégicos de desenvolvimento são flexíveis e mais vocacionados para a demonstração das potencialidades de um dado lugar do que para um programa exato, e mais vocacionados para a comunicação de ideias do que para a regulação do uso do solo (Lake, 2012).

Por não apresentar um quadro estático, o planeamento estratégico fornece as referências, linhas de orientação que servirão para apoiar as decisões e os processos de planeamento territorial. Além disso, o planeamento estratégico é encarado como um 
processo cíclico ao contrário do planeamento tradicional cujo objetivo consistia na aprovação do plano definitivo, que constituía um produto acabado. Tratase de um processo de planeamento contínuo, onde devem ser definidas as metas de desenvolvimento, as suas prioridades de atuação e os programas de ação e que exige a organização de um sistema eficiente de acompanhamento e monitorização (Alexandre, 2003; Lake, 2012; Bütüner, 2016).

Segundo Fonseca (2006), a finalidade do planeamento estratégico visa identificar, hierarquizar e programar os recursos mobilizadores de crescimento de um território, com base no diagnóstico dos problemas e das tendências de evolução que bloqueiam o desenvolvimento socioeconómico e territorial, bem como os fatores de desenvolvimento externos, em termos de: políticas setoriais que tenham repercussões no desenvolvimento territorial; iniciativa e capacidade de empreendimento por parte dos atores/ instituições locais; constituição de parcerias público/ privado, incrementando uma cultura de partilha de responsabilidades e desenvolvimento de uma base coerente e fundamentada de apoio à decisão. Para além disso, o planeamento estratégico tem como objetivo definir e realizar um projeto de cidade com o intuito de reforçar a competitividade, melhorando a qualidade de vida de todos os cidadãos.

Reconhecendo as claras limitações impostas pelo planeamento tradicional, o município da Lousã tem vindo a desenvolver um processo de planeamento estratégico, numa clara perspetiva do que Mendes (2012) considera como um território proativo, criando simultaneamente uma oportunidade de participação, empenho e mobilização dos diferentes atores territoriais na elaboração de um projeto de desenvolvimento para o território.

\section{O plano estratégico da Lousã no horizonte 2031}

O plano estratégico do município da Lousã visa definir e realizar um projeto de território, reforçando a competitividade e melhorando a qualidade de vida de todos os cidadãos que lá residem. Para tal, este processo pretende unificar visões, coordenar a atuação pública e privada e estabelecer um quadro coerente de mobilização e cooperação dos atores com relevância no território.
De facto, "num ambiente de grande complexidade, o planeamento estratégico surge como uma metodologia prospetiva que integra as múltiplas variáveis e determinantes" (Ferreira, 2005). Deste modo, a metodologia de elaboração do plano estratégico considerou sequencialmente um primeiro momento traduzido num diagnóstico, seguido da definição de uma estratégia e a concretização da estratégia num conjunto de ações/projetos.

A fase de diagnóstico retrata a situação atual do município da Lousã em diversas áreas fundamentais e estruturantes (Figura 1). A sistematização do diagnóstico é realizada com base num quadro swot no qual se destacam as grandes forças e oportunidades e as fraquezas e ameaças, quer no contexto interno, quer no contexto externo.

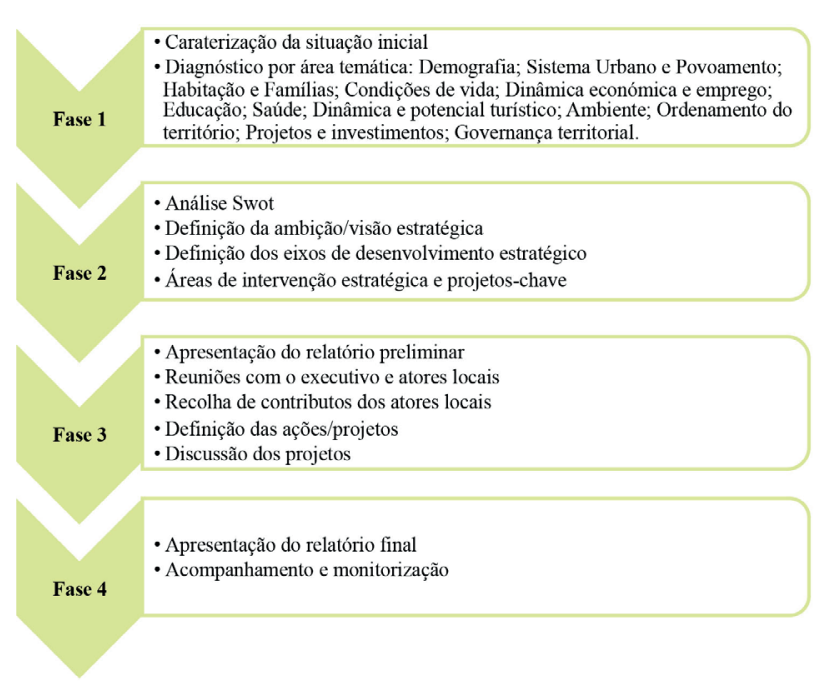

Figura 1 - Metodologia de elaboração do Plano Estratégico da Lousã Fonte: Autores.

0 exercício de apresentação de uma estratégia e a definição de ações/projetos tem presente o contexto territorial, os ativos específicos e as potencialidades identificadas no quadro das possibilidades decorrentes da política e dos instrumentos de financiamento desenhados para a região e para o país. Deste modo, a definição da Estratégia para o território procura garantir o alinhamento com os novos desígnios estratégicos globais, assim como com o novo quadro de programação financeira a nível europeu (Europa 2020). A formulação de uma estratégia de futuro teve como objetivo primordial "tornar um território mais competitivo, do ponto de vista económico e de o dotar de uma maior coesão social e habitabilidade" (Fonseca, 2006). 
A fase 3 pressupõe a participação ativa e informada de todos, câmara municipal, instituições públicas e privadas, empresas, associações locais e população, sendo que a câmara assumiu a liderança, definindo caminhos e avançando com propostas, sempre de forma partilhada e imprimindo uma dinâmica que procure mobilizar todos. Este plano, a exemplo de qualquer plano estratégico, não se encerra com um documento. Este é o início de um processo contínuo de acompanhamento, avaliação e monitorização (fase 4), que deve promover as dinâmicas de correção e adaptação proativa aos novos contextos que forem surgindo.

Num momento de arranque efetivo do novo quadro comunitário de apoio através do programa Portugal 2020, Portugal irá receber cerca de 25 mil milhões de euros de fundos europeus, sendo que uma parte substancial deste montante se destina ao fomento do desenvolvimento inteligente, sustentável e inclusivo das regiões. Lousã não poderá passar ao lado desta oportunidade de financiamento, devendo definir as suas prioridades de investimento de acordo com os objetivos definidos pelos documentos orientadores estratégicos, designadamente a estratégia Europa 2020, Portugal 2020, CRER 2020. Este último, referente à estratégia do Programa Operacional Regional do Centro (2014-2020) estrutura-se em 9 eixos prioritários $^{2}$, mobilizando 10 objetivos temáticos ${ }^{3}$ e 29 prioridades de investimento. Este programa, alinhado com a estratégia Europa 2020, Portugal 2020 e com a Estratégia de Investigação e Inovação para a Especialização Inteligente (RIS 3), tem como prioridades, até 2020 , sustentar e reforçar a criação de valor e a transferência de conhecimento, promover um tecido económico industrializado, competitivo e

\footnotetext{
2 Eixo 1: Investigação, Desenvolvimento e Inovação (IDEIAS); Eixo 2: Competitividade e Internacionalização da Economia Regional (COMPETIR); Eixo 3: Desenvolver o Potencial Humano (APRENDER); Eixo 4: Promover e Dinamizar a Empregabilidade (EMPREGAR e CONVERGIR); Eixo 5: Fortalecer a Coesão Social e Territorial (APROXIMAR e CONVERGIR); Eixo 6: Afirmar a sustentabilidade dos recursos (SUSTENTAR); Eixo 7: Afirmar a sustentabilidade dos territórios (CONSERVAR); Eixo 8: Reforçar a capacitação institucional das entidades regionais (CAPACITAR); Eixo 9: Reforçar a rede urbana (CIDADES) e Eixo 10: Assistência técnica.

3 OT 1: Investigação, desenvolvimento tecnológico e a inovação; OT 2: TIC; OT 3: Competitividade das pequenas e médias empresas; OT 4: Economia com baixa emissão de carbono; OT 6: Ambiente e eficiência dos recursos; OT 8: Emprego e mobilidade laboral; OT 9: Inclusão social e combate à pobreza; OT 10: Ensino e aprendizagem ao longo da vida; OT 11: Administração pública eficiente.
}

exportador, captar e reter talento qualificado e inovador, reforçar a coesão territorial, estruturar uma rede policêntrica de cidades de média dimensão, dar vida e sustentabilidade a infraestruturas existentes e consolidar a capacitação institucional. Tal como o anterior quadro comunitário, a dimensão territorial na Política de Coesão da União Europeia tem acolhimento no Centro 2020 através de diferentes abordagens, nomeadamente, Investimentos Territoriais Integrados (ITI), Desenvolvimento Local de Base Comunitária (DLBC), Ações Integradas de Desenvolvimento Urbano Sustentável (AIDUS) e Estratégias Territoriais Específicas (PROVERE). Em termos de dotação financeira, o Centro 2020 terá uma dotação de 2.155 mil milhões de euros, dos quais 1.751 mil milhões de euros do Fundo Europeu de Desenvolvimento Regional (FEDER) e $404 \mathrm{mi}$ lhões de euros do Fundo Social Europeu (FSE).

Neste contexto, entende-se que o plano estratégico de Lousã poderá ser uma oportunidade que leve ao desenvolvimento efetivo do território e contribua para alavancar a economia e para elevar a qualidade de vida de todos os cidadãos. 0 principal objetivo será o de tornar Lousã um território mais coeso, mais atrativo, mais resiliente e mais competitivo, o que no momento atual só se consegue efetivar com uma educação, formação diferenciada e de qualidade superior.

\section{O território}

Localizado no centro de Portugal continental, o município da Lousã faz parte da Comunidade Intermunicipal da Região de Coimbra (território que integra 19 municípios). Com uma área de 138 $\mathrm{km}^{2}$ e 17.604 habitantes, o território concelhio subdivide-se em quatro freguesias com dinâmicas demográficas e socioeconómicas distintas.

Em termos de bases físicas do território, o município da Lousã apresenta um importante setor de montanha e de grande riqueza natural. Desenvolvido na sua totalidade no Maciço Hespérico, apresenta uma morfologia bastante diferenciada, marcada pela serra da Lousã no seu setor sudeste, a qual representa a extremidade sudoeste do mais importante bloco montanhoso do país, a Cordilheira Central, e pela bacia da Lousã no setor central, onde reside a esmagadora maioria dos habitantes deste território (Figura 2). 


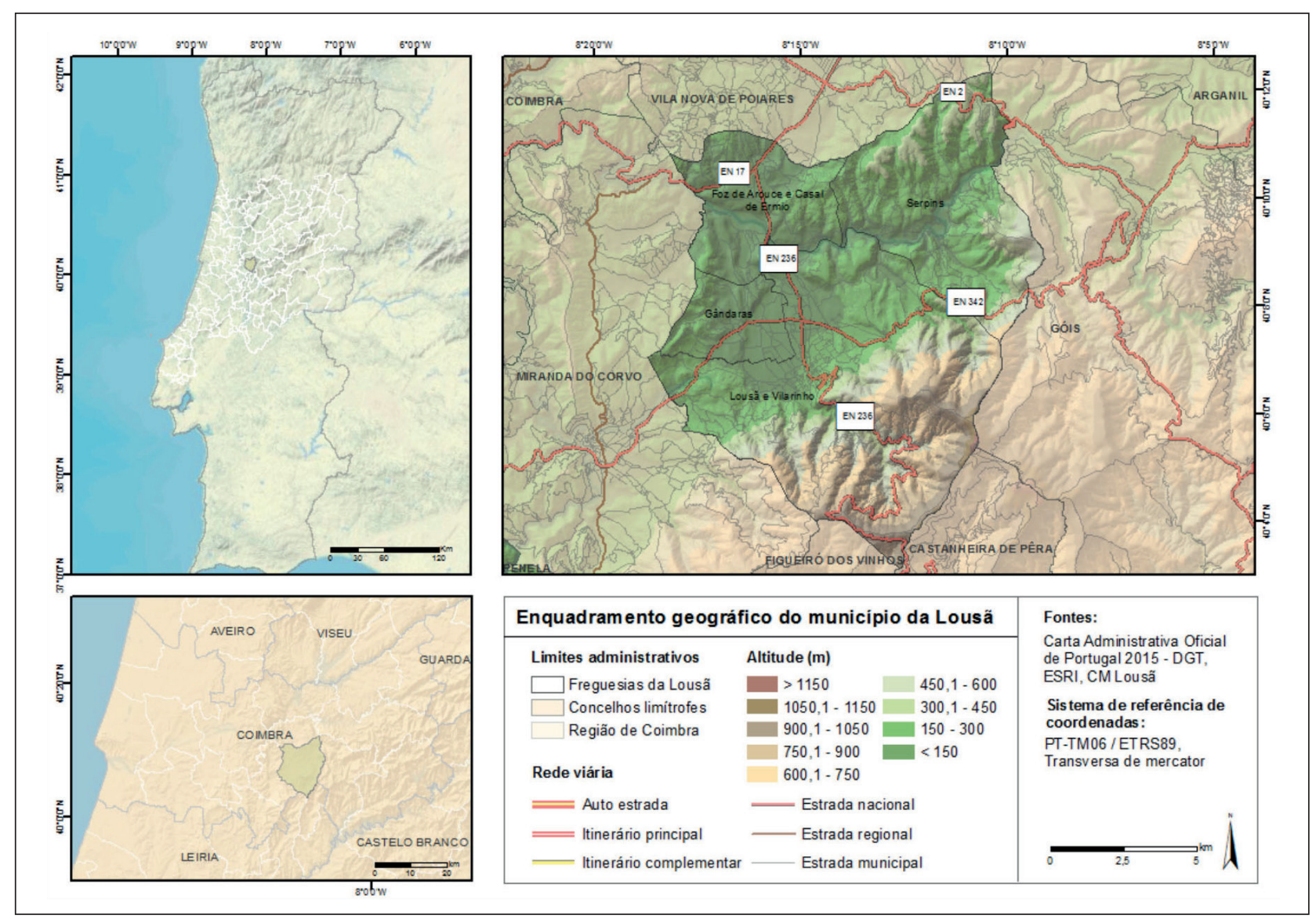

Figura 2 - Enquadramento geográfico do municíio da Lousã Fonte: Autores.

As alterações demográficas e económicas devem ser entendidas num quadro mais vasto de relacionamento deste município com outros territórios próximos, nomeadamente Coimbra, uma vez que, desde há muito tempo, beneficia de uma posição estratégica associada à Estrada Nacional 17 que funciona como via preferencial de ligação entre o município, Coimbra e Guarda. Por outro lado, esta evolução também deve ser entendida num quadro da proximidade aos principais aglomerados urbanos da região - Coimbra e Figueira da Foz - e também da região de Leiria Pombal e Leiria (Cordeiro (coord), 2015).

A densidade populacional para o concelho da Lousã (127,2 hab/km2) assume valores superiores aos do Continente (112,8 hab/km2), sendo, no contexto da Região de Coimbra, apenas ultrapassado pelos conselhos de Coimbra, Mealhada e Figueira da Foz. 0 fenómeno do envelhecimento populacional é menos marcado neste território, sendo este o conselho da Região de Coimbra com o mais baixo valor do índice de envelhecimento (114,2\%). Este cenário encontra paralelismo na observação do peso da população com menos de 24 anos, sendo este o concelho com um maior peso dos jovens na sua estrutura etária (26\%), valor superior à média da Região $(22,8 \%)$ e do próprio espaço continental português $(25,5 \%)$.

As relações funcionais que se observam entre os diversos municípios deste território e, em especial, com Coimbra, ajudam assim a compreender a evolução demográfica (crescimento de 11,7\%) e económica recente. A Lousã tem funcionado nas últimas décadas numa lógica de "dormitório" de Coimbra.

Salientam-se como atividades responsáveis pela dinâmica económica, as atividades secundárias, nomeadamente a transformação de papel, os componentes elétricos, o azeite, os vinhos e os licores. No que diz respeito às atividades terciárias, destacam-se particularmente os serviços e o comércio. Paralelamente, o turismo contribui fortemente para o desenvolvimento do município com um forte fluxo de visitantes, quer 
considerando a Serra da Lousã e as Aldeias do Xisto ${ }^{4}$, quer o rico e variado património histórico/edificado e natural existente.

Em termos do perfil de habilitações literárias da população residente, e tal como foi anteriormente referido, constata-se que há uma clara desqualificação escolar, observando-se que cerca $57 \%$ não tem mais do que o $3^{\circ}$ ciclo do ensino básico, cerca de 18,4\% não apresenta nenhum nível de escolaridade e apenas 9,8\% apresenta um nível de habilitações superior à licenciatura, facto que obriga a uma reflexão no contexto da estratégia a desenvolver no quadro da educação do município (Cordeiro, 2015).

Por último, a posição de interface entre o interior e o litoral do Centro, a Serra e os espaços urbanos (Coimbra) facilita a fixação e atração de visitantes, residentes e investimentos. Trata-se de um território com uma diversidade de paisagens, de elementos naturais e de património, de cultura traduzidos numa identidade e marca a valorizar (Tomás, 2005). A proximidade a uma área urbana fortemente associada à criação de conhecimento, ao ensino e à investigação, aos serviços de saúde permite que a Lousã possa capitalizar a sua localização num quadro de criação/melhoramento da rede rodoviária e ferroviária (metro de superfície Coimbra-Serpins).

\section{A Estratégia de desenvolvimento. Visão e eixos estratégicos}

Num contexto de abertura global dos territórios, a existência de elementos singulares, específicos e que valorizem os novos fatores distintivos de localização assentes no conhecimento e nas competências individuais e coletivas assumem-se com a chave para a competitividade de empresas e territórios. A competitividade (ou o desenvolvimento) é a capacidade de

\footnotetext{
4 A Rede das Aldeias do Xisto é um projeto de desenvolvimento regional sustentável, desenvolvido em 27 aldeias, em colaboração entre vários municípios da região centro (16), agentes privados, associações de desenvolvimento e outros atores locais, visando a melhoria da qualidade de vida dos residentes e a promoção turística deste território, criando riqueza através da oferta de serviços turísticos em conjugação com a preservação da cultura e paisagens, a dinamização das artes e dos ofícios tradicionais, do património e dos produtos locais característicos das aldeias que integram a rede (Barros \& Gama., 2010).
}

criar continuamente valor e emprego, num ambiente concorrencial e de abertura, permitindo aumentar e repartir rendimentos, promovendo a qualidade de vida de forma sustentada e sustentável. A leitura feita a partir de um diagnóstico territorial permitiu identificar para a Lousã um conjunto de fatores distintivos da competitividade que devem ser considerados e valorizados quando se elabora uma estratégia de desenvolvimento do município para as próximas duas décadas (Cordeiro, 2016).

A existência de uma base económica relativamente diversificada, mas com áreas chave (fileira agroindustrial e florestal, papel, material elétrico, produtos metálicos e vestuário, cadeia de valor do turismo e atividades de serviços), assim como uma população jovem permite estruturar uma estratégia que valorize a formação e qualificação dos recursos humanos e a criação contínua de conhecimento essencial para a inovação não apenas empresarial, tecnológica, mas também social e institucional. Neste âmbito, a dimensão institucional e associativa é decisiva para o funcionamento de todo o sistema económico e social, sobretudo se for capaz de antecipar tendências e facilitar a circulação de informação no quadro de um modelo de governação que privilegie a cooperação, liderando processos e articule todos os agentes territoriais, promovendo relações entre si, procurando igualmente abrir-se ao exterior na procura de soluções para a qualificação de todo o sistema socioeconómico. A valorização das potencialidades associadas às TIC afigura-se decisiva não apenas no território, mas sobretudo na captação e incorporação de saberes e recursos, atraindo pessoas e investimento, promovendo a identidade e a marca associada ao território.

A concretização das oportunidades tem que ser pensada, não apenas no quadro de uma aposta inequívoca nas conectividades e nas articulações com os espaços geográficos de vizinhança, mas também com os lugares mais distantes. A definição de eixos naturais de contacto, de corredores privilegiados de relações, é aqui, uma etapa fundamental. Contudo, nessa Lousã conectada, é relevante não deixar escapar o conceito de integração vertical das escalas geográficas. Um lugar estrategicamente bem posicionado é aquele que se afirma em múltiplos patamares territoriais, do local ao regional, do nacional ao peninsular e europeu, devendo estes ser vistos não como patamares espaciais separados e fragmentados, mas como referências que se sistematizam e plasmam, em conjunto, em cada 
lugar. Esta conectividade faz-se pelas infraestruturas, mas também pelas pontes institucionais, pelas mobilidades e pelos fluxos, pelas iniciativas empresariais e outras, com especial destaque para a educação.

A ambição da política de desenvolvimento estratégico para o município para as próximas décadas deverá assim assentar num contexto em que, em termos de missão, a Lousã deve assumir-se:

1) como um território de criação de valor e emprego, numa lógica de fixação de pessoas;

2) como um território de encontro e convívio, solidariedade e coesão;

3) como um território de sustentabilidade ambiental;

4) como um território de governação democrática, participada e eficiente.

Neste quadro, a Lousã horizonte 2031 deve Qualificar o Território, Capacitar os Recursos, Criar Oportunidades e Mobilizar Redes. Assim, assumem-se como dimensões desta visão estratégica:

- Lousã território sustentável, de referência ambiental e que valorize os recursos e o quadro natural;

- Lousã destino turístico, de referência nas vertentes ativa e inclusiva e das aldeias do xisto;

- Lousã território competitivo e inclusivo, de referência na qualificação das pessoas, na inovação e no empreendedorismo;

- Lousã polo de excelência no contexto regional e nacional, de referência na valorização do posicionamento e da inserção regional e global.

A ambição que sustenta a estratégia para a Lousã horizonte 2031 "Qualificando o Território, Capacitando os Recursos, Criando Oportunidades e Mobilizando Redes" para o desenvolvimento integrado e inclusivo, exige que sejam valorizados os recursos e as capacidades endógenas no quadro dos novos fatores de localização e fixação de pessoas e investimentos (criatividade, conhecimento e inovação) e de complementaridades de setores produtivos (agricultura, floresta, indústria, turismo e serviços). A visão/ ambição estrutura-se em cinco eixos estratégicos (um estruturante e quatro operacionais) e dois transversais (Figura 3).

0 Eixo 1, sendo estruturante, deve ser entendido no quadro da criação de condições para o desenvolvimento inteligente, sustentável e inclusivo dos territórios da Lousã (Lousã Serra e Bacia da Lousã, nas quais se observam a Lousã Urbana e a Rural). Deverá valorizar intervenções e projetos no domínio do espaço público, do património material, das acessibilidades e comunicações e dos equipamentos e das infraestruturas de localização das atividades.

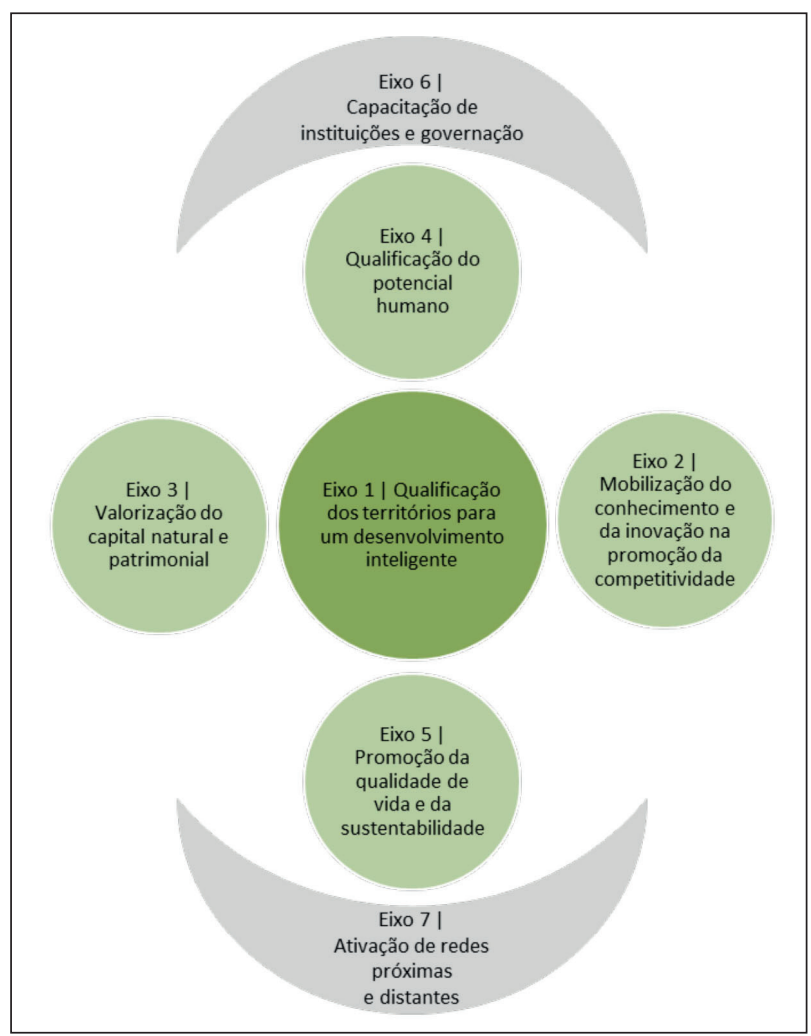

Figura 3 - Estratégia de desenvolvimento para a Lousã Fonte: Autores.

No que diz respeito aos restantes eixos temáticos salienta-se o eixo 4 - Qualificação do potencial humano, tendo este como objetivo o de elevar a qualificação de jovens e adultos, promovendo a sua empregabilidade e a adequação das suas qualificações às necessidades do desenvolvimento sustentado, de aumento da competitividade e de coesão social do território municipal.

Reconhece-se que o perfil de qualificações do município da Lousã constitui um dos principais entraves ao desenvolvimento de atividades produtivas mais intensivas em conhecimento e criatividade, com repercussões negativas ao nível da produtividade e da competitividade da sua economia local. As baixas qualificações são também encaradas como um sério obstáculo ao desenvolvimento pessoal dos cidadãos, ao exercício de uma cidadania ativa e à empregabilidade.

No atual quadro de programação financeira 20142020, há uma preocupação real com esta temática, prevendo-se que os fundos comunitários sejam mobilizados para a resposta adequada aos problemas 
identificados. Em particular, será dada prioridade à diversificação das vias de ensino, nomeadamente através do reforço das vias vocacionais e profissionalizantes, com um forte pendor da formação em contexto de trabalho, visando a tripla função de recuperar jovens com percursos de insucesso, acolher jovens com percursos escolares regulares e aumentar o volume de ativos jovens com competências reconhecidas pelas entidades empregadoras. Paralelamente, no que diz respeito à população adulta com baixas qualificações, a aprendizagem ao longo da vida encontra-se no cerne das prioridades das intervenções públicas, tendo como objetivos o aumento da empregabilidade, bem como a promoção de uma cidadania ativa e qualificada.

A materialização destes eixos estratégicos desenvolve-se em três níveis -ações/projetos âncora; ações/projetos facilitadores e ações/projetos setoriais -, pressupondo uma coerência e uma articulação para as intervenções e a disponibilidade de recursos financeiros no âmbito da estratégia nacional Portugal 2020.

A Estratégia preconizada para a Lousã assenta na implementação de um conjunto de projetos em diferentes áreas de intervenção temáticas. Estas áreas, definidas com base na leitura do diagnóstico, devem ser catalisadoras de novas dinâmicas no processo de transformação do território.

Abarcando uma diversidade temática e ajustadas à visão futura para a Lousã devem impulsionar um efetivo processo de dinamização do tecido económico e social e de requalificação urbana e ambiental.

As propostas pretendem, assim, qualificar os recursos e ativos existentes no quadro da especialização inteligente, visando a criação de novas dinâmicas (sociais, culturais, económicas e institucionais) e de um território mais coeso e inclusivo.

Propõem-se, assim, 13 áreas de intervenção, nas quais deverão recair os projetos estruturantes a implementar no município. Estas áreas abarcam elementos físicos, ambientais, urbanos, sociais, culturais, económicos, de turismo e lazer, de governança, entre outros.

A título de exemplo, apresentam-se apenas as ações/projetos âncora uma vez que a área temática da educação aparece plasmada nesta área de intervenção nomeadamente no ponto A.1. Educação, formação e desporto e na tipologia de ação a.1.1. Território Educativo (Figura 4).

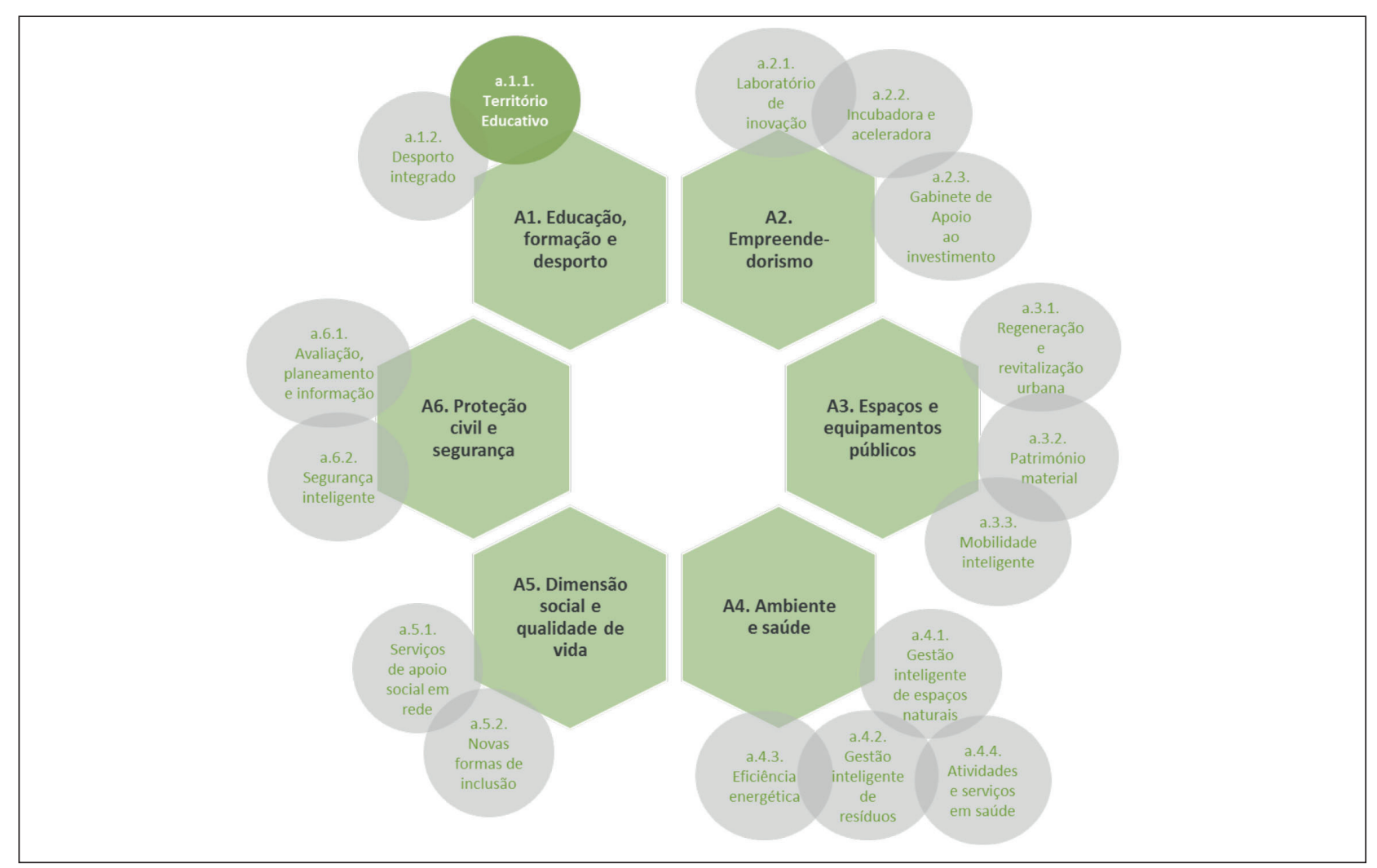

Figura 4 - Áreas de intervenç̃o estratégica - ações/projetos âncora

Fonte: Autores. 
Enquadrado nesta tipologia de ação e em consonância com o eixo 4 - Qualificação do potencial humano, o "Projeto Educativo Local" pretende criar políticas públicas de educação e formação, associando-as a determinadas opções de desenvolvimento. Este, por sua vez, nunca poderá ser separado dos recursos e dinâmicas existentes ou passíveis de ser mobilizadas e desenvolvidas no território. 0 projeto apela, assim, ao recurso a novas formas de gestão autárquica, consolidando práticas políticas comprometidas com a transformação diária da vida das pessoas e das diferentes comunidades, envolvendo-as e corresponsabilizando-as numa ação continuada.

\section{A educação no quadro do plano estratégico da Lousã}

\section{O Projeto Educativo Local como impulsionador de oportunidades educativas em todos os espaços e ao longo da vida}

O Projeto Educativo Local do município da Lousã assume-se, desde o início da sua conceção, como um plano estratégico educativo municipal de carácter inclusivo, que reúne os diferentes atores locais na construção e dinamização de ações que devem vir a dar resposta a necessidades dos cidadãos, perspectivando (trans)formação social e cívica na comunidade. Neste sentido, vem desde algum tempo a ser atribuído à educação pelo executivo autárquico um papel fulcral de desenvolvimento do território, assumindo-se que este, desde há muito, influenciou e é influenciado por ela. Num plano deste cariz, a educação é analisada, claramente, de uma forma global, tendo como premissa fulcral o reforço de uma cidadania ativa e participativa, que alicerça o sistema democrático que gere o território, acontecendo ao longo da vida, desde a fase pré-natal ao adulto mais idoso, incluindo, nas suas linhas de ação, estratégias associadas à educação não só formal, mas também à não formal e informal.

Encarado como um instrumento de caráter estruturante, regulador das orientações estratégicas e das práticas educativas para o território, o plano estratégico para a educação da Lousã, encontra-se suportado por uma metodologia de projeto participada, implicando uma configuração metodológica baseada em processos dinâmicos - diagnóstico, planeamento, implementação e avaliação. Reforça-se, ainda, a partilha do compromisso e da responsabilidade educativa entre os atores educativos, num determinado espaço com identidade própria e objetivos partilhados como é o do território do município, obrigando sempre a um compromisso de monitorização e avaliação ao longo da vigência do plano.

Como se pode constatar, e tendo como base a premissa fulcral que só conhecendo a fundo a realidade que o sistema educativo do município apresenta se pode delinear de forma efetiva o futuro, torna-se fundamental, na concretização do PEL, o definir de algumas questões orientadas para a necessidade de conhecer bem o território e suas características, realizando um bom diagnóstico, como ponto de partida, e também para a importância de planear o sistema educativo do território a uma década - claramente geracional. Neste contexto, o envolvimento dos diferentes atores existentes é crucial, não esquecendo que a educação é mais do que a "escola", que acontece em diferentes espaços e áreas de intervenção, e que o território e as suas características materiais e imateriais devem ser potencializados com a educação.

Afirma-se, portanto, que PEL deve assumir um papel de destaque na planificação de ações que possam contribuir para uma educação holística e contínua dos seus cidadãos, no quadro de um plano estratégico de desenvolvimento sustentável de um determinado território (Cordeiro et al., 2012; Alcoforado, 2014), devendo, por isso, integrar uma equipa alargada de profissionais e atores do território que se devem organizar em torno de projetos concretos, bem definidos e participados por todos.

Efetivamente, o PEL da Lousã desenvolve-se em paralelo com o Plano Estratégico de Desenvolvimento, num processo que tende, em cada momento, a incluir novas reflexões e contribuições, desenhando-se, assim, no quadro lógico de que apenas a caminhar é possível identificar as condições mais favoráveis e os destinos mais desejáveis e acreditando, por outro lado, que as melhores soluções não podem ser encontradas através de fórmulas mágicas, únicas ou definitivas, num processo com as características como aquelas que aqui se pretendem conjugar (Cordeiro et al., 2012).

O desafio do projeto educativo do município da Lousã deverá pautar-se por envolver todos os cidadãos em processos educativos ao longo e em todos os espaços das suas vidas, proporcionando-lhes os 
recursos necessários para uma participação ativa na transformação dos seus grupos de pertença e contextos de proximidade, desafiando-os a contribuir para processos de globalização ascendente, assentes em comunidades educadoras locais.

É, ainda, fundamental que o PEL cuide de garantir que todos os espaços sociais do território se constituam como espaços educativos, chamando a uma participação ativa quem neles trabalha, quem os procura e deles usufrui. Nesse sentido, é intuito deste projeto a assunção de que os locais de trabalho sejam progressivamente baseados na possibilidade de disponibilizar oportunidades de convocação e construção contínua de novos saberes e competências. As empresas e todas as instituições socioeconómicas têm vindo ser convocadas a este esforço formativo da comunidade, contribuindo para a compreensão das necessidades de formação e comprometendo-se com este objetivo de valorização de todos os trabalhadores e do território em geral. Será igualmente importante valorizar e acolher, quer as capacidades individuais para inovar e empreender, quer as iniciativas grupais para gerar formas alternativas e solidárias de produção. No entanto, para além do tecido socioeconómico, também os serviços públicos, os espaços patrimoniais e todo o movimento associativo se encontram a participar no projeto.

Salienta-se, desta forma, a importância que o PEL encerra ao nível do apoio na identificação, na articulação e mesmo na construção de espaços públicos de educação no território, espaços que se entendam como verdadeiramente educadores e cujo planeamento pedagógico seja uma realidade, contribuindo para a construção contínua de como se pode ser cidadão. Para que isto aconteça, é importante que se planeie o território atendendo ao que se considera ser um território como ambiente de aprendizagem, muito para além dos espaços escolares (Figura 5).

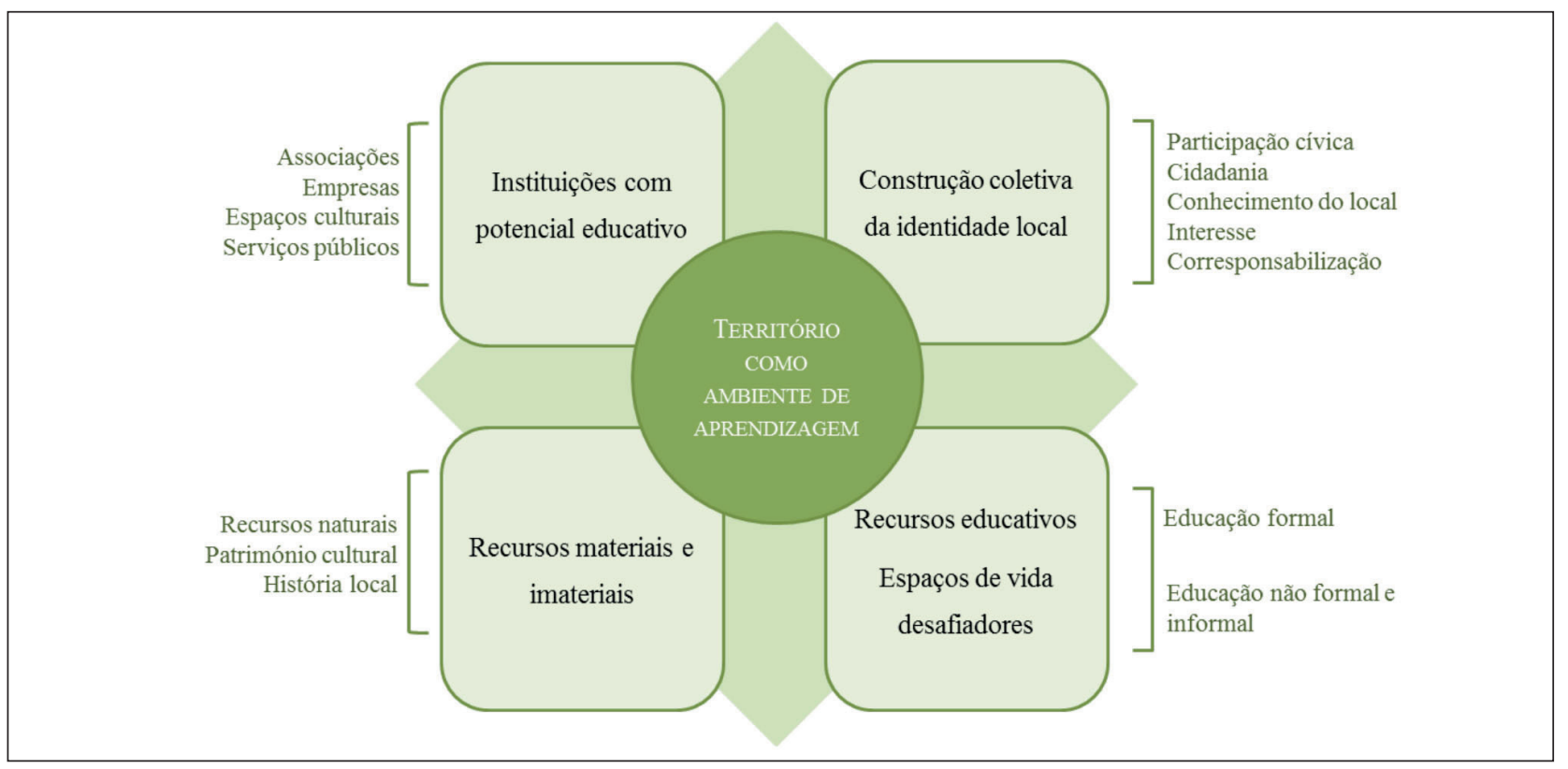

Figura 5 - Território como ambiente de aprendizagem

Fonte: Autores.

0 potencial dos espaços de educação não formal para o desenvolvimento de aprendizagens significativas é inegável, dado aumentar a possibilidade de os indivíduos se envolverem numa multiplicidade de atividades enriquecedoras e complementares às realizadas no âmbito da educação formal. Assim, urge entender o território como ambiente de aprendizagem que multiplica as oportunidades educativas para todas as faixas etárias, privilegiando uma estreita articulação com a comunidade local e, em simultâneo, a gestão integrada dos recursos e o desenvolvimento de atividades de âmbito educativo, cultural, social e desportivo. De referir que, no âmbito do PEL, todos estes pressupostos conduzirão à construção de um mapa de espaços com potencial educativo do território. 
Pretende-se, como se constata, que a ideia do "local" possa envolver-se numa construção coletiva que reforce a ideia de democracia participativa, levando a um maior envolvimento dos indivíduos na construção de políticas de desenvolvimento sustentável nos diferentes prismas de análise e que a ideia de trabalho em "rede" se continue a implementar no território.

\section{Eixos estratégicos para educação no município da Lousã}

Assumido como um projeto estratégico para a educação, o PEL da Lousã emerge como um compromisso estabelecido entre o município, as escolas e toda a comunidade educativa, definindo um conjunto de princípios e estratégias para a construção de um modelo educativo intimamente ligado à visão de desenvolvimento do território e a toda a lógica anteriormente referida sobre o planeamento estratégico.

Tendo em linha de conta todos os pressupostos até agora enunciados, assentes numa lógica de educação e formação em todos os espaços e ao longo da vida, o PEL da Lousã encontra-se estruturado num conjunto de eixos estratégicos (alguns diretamente associados ao Plano Estratégico de Desenvolvimento), que se traduzirão em desafios de mudança com objetivos bem definidos e que, consequentemente, potenciarão a estratégia educativa para o município da Lousã. Inerente a esta estratégia apresenta-se, assim, uma diversidade de ações/atividades que devem ser realizadas de forma articulada e organizada, seguindo uma sequência lógica que assegure racionalidade e participação dos atores locais ao longo de todo o processo e, em particular, no decisório, levando a uma efetiva alteração e transformação geracionais da área educativa. Esta sequência de atividades deve, por um lado, combinar o processo técnico e a negociação política e, por outro, integrar a forma ascendente e descendente de análise e formulação de prioridades.

Os grandes desafios passaram, desde logo, e num primeiro momento pelo adequar do parque escolar às necessidades efetivas do território educativo, em conformidade com a concretização da carta educativa municipal de $2^{\text {a }}$ geração. Os restantes eixos estruturantes orientam-se para a promoção do sucesso educativo e promoção da educação não formal e informal. Importante será dizer que algumas dos eixos/ áreas de intervenção encontram relação direta com o Plano Estratégico de Desenvolvimento, designadamente, a área da Inovação e Competitividade e a da promoção dos níveis de qualificação da população. De referir, ainda, que tanto a área da inovação e competitividade, como a da governança na educação constituem áreas transversais a todas as outras já mencionadas (Figura 6).

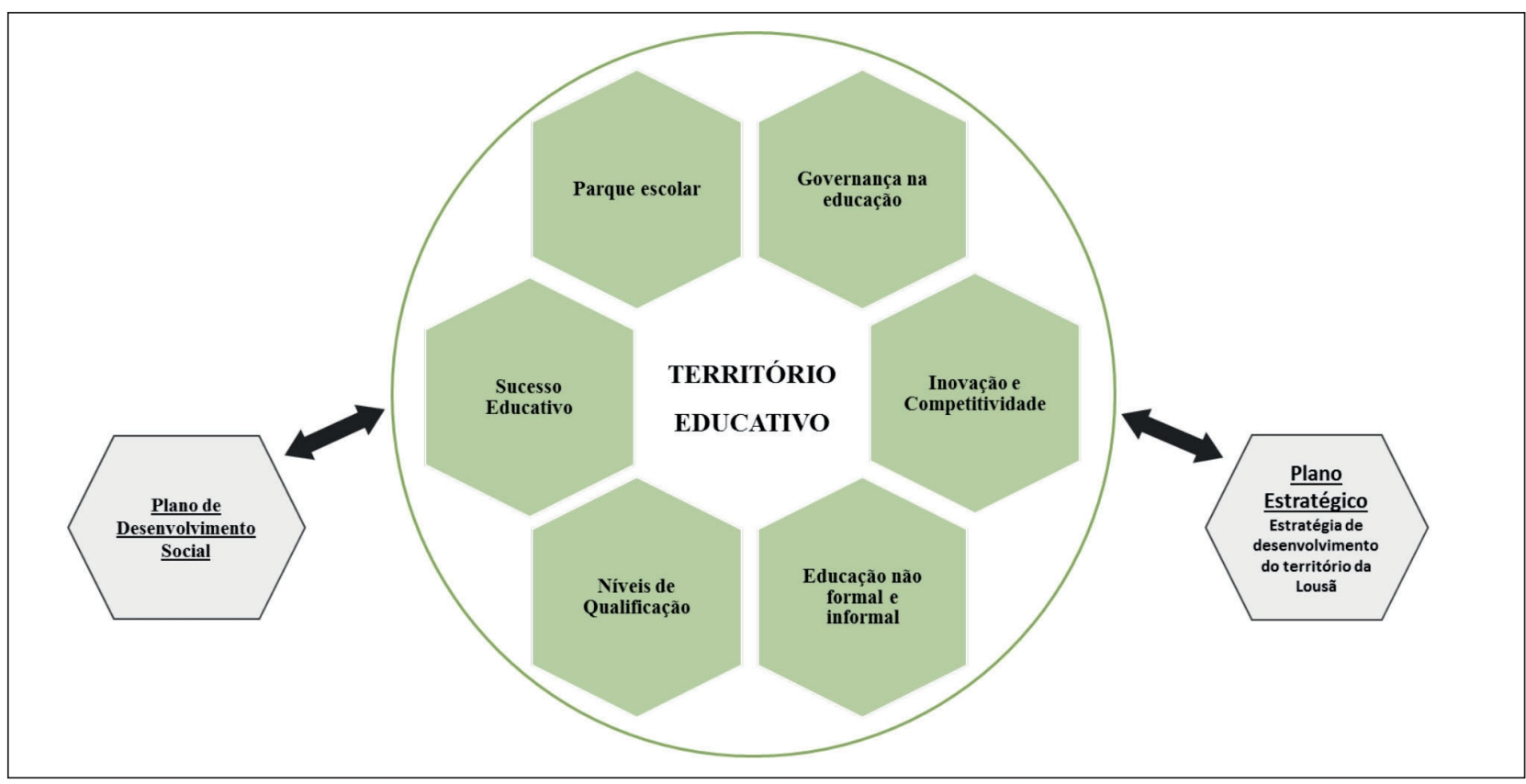

Figura 6 - Projeto Educativo Local da Lousã: os grandes desafios (açã̃o a.1.1. do Plano Estratégico de Desenvolvimento da Lousã) Fonte: Autores. 
A estes desafios, encarados como oportunidades de mudança, foram associados objetivos, possibilitando a construção de estratégias, projetos e ações adequadas à concretização das transformações desejadas.

Desta feita, e no que diz respeito à adequação do parque escolar às necessidades do território, o principal objetivo/missão foi o de garantir uma rede escolar de qualidade, com as condições necessárias para o desenvolvimento das diferentes atividades educativas, pelo que foi reorganizada a rede, com um amplo debate com os diferentes atores - professores, pais e restante população - e que esteve na base do encerramento de escolas que não apresentassem 4 salas de aula (lógica de um professor, uma sala e um ano de ensino), com a consequente passagem desses alunos para uma nova e moderna escola, muito do que foi referido no contexto da análise sobre o insucesso escolar na CIM Região de Coimbra (Cordeiro \& Alcoforado (coord), 2015). Aliás, com base neste mesmo projeto, o assumir de um eixo sobre a promoção do sucesso educativo tornava-se fulcral. Os objetivos neste eixo 2 passam, deste modo, por garantir que todas as crianças a partir dos 3 anos de idade tenham acesso à educação pré-escolar; melhorar os resultados escolares dos alunos do município e diminuir as taxas de retenção; disponibilizar espaços e tempos de enriquecimento e apoio curricular que reforcem o conhecimento das crianças sobre os recursos do território e promovam uma educação holística e atitudes mais participativas; diminuir e prevenir comportamentos de risco dos alunos ao nível da violência e de eventual consumo de substâncias psicoativas e de álcool; otimizar o acesso dos jovens à informação e orientação educativa e profissional, desafiando-os a construir projetos de vida; reforçar o apoio às crianças e jovens referenciados com necessidades educativas especiais; e criar condições de acesso do pessoal não docente a programas de formação contínua.

Relativamente à elevação dos níveis de qualificação da população, pretende-se garantir oportunidades de formação e/ou qualificação para todos os jovens e adultos, trabalhando em articulação entre as escolas (Escola Secundária e Escola Profissional), o setor empresarial e a própria autarquia. Um dos pontos fulcrais da nova visão para a educação passa, portanto, pela criação, de forma concertada - agentes educativos, empresários, outros parceiros -, de uma oferta diversificada e adaptada às necessidades do município em termos de ensino profissional e tecnológico, pela implementação de um sistema de orientação vocacional que preveja e evite situações de insucesso e de abandono do percurso escolar e formativo por parte da população jovem.

A educação não formal e informal deverá ser alvo de atenção, principalmente no que diz respeito à garantia de um envelhecimento ativo de toda a população sénior e idosa, na promoção da inclusão da população em situação de vulnerabilidade social, por meio de ações que contribuam para a sua formação pessoal e profissional e no reforçar da participação nas atividades do associativismo.

A implementação de estratégias que fomentem a inovação e a competitividade do município assume-se de forma integrada com o Plano Estratégico de Desenvolvimento, representando, entre outras ações, a criação de uma oferta educativa diferenciadora que potencie a atratividade do território.

Tal como a área da inovação e competitividade, também a área da governança na educação se constitui como um eixo transversal, emergindo como um conceito recente e incontornável, cujo desafio se centra na procura de soluções para as melhores formas de gestão da educação, atendendo à multiplicidade das inter-relações estabelecidas entre os diversos atores sociais integrados no território. Na verdade, encontra-se cada vez mais evidente a ideia e a necessidade de trazer novas lógicas de governança para a educação, considerando o trabalho em rede como o caminho a seguir rumo ao bem comum da comunidade educativa. Neste contexto, pretende-se efetuar um acompanhamento regular e adequado do percurso educativo e das transições dos jovens no município da Lousã, garantir um acompanhamento e reforço da ação das escolas no âmbito da intervenção psicoeducativa e orientação vocacional, numa estreita relação entre a rede escolar e outros serviços locais, bem como incentivar a participação cívica dos jovens na sociedade.

Embora do ponto de vista estratégico se assuma como um projeto com princípio, meio e fim, o PEL do município da Lousã, face aos diferentes eixos estratégicos definidos, desenvolve-se como uma estratégia permanentemente construtiva, onde se deverá sempre melhorar e acrescentar mais atividades e envolvimento, procurando o desenvolvimento 
de políticas locais. Ao serem participadas por mais atores, desenvolve-se com contributos cada vez mais ricos e numa base de mudança cultural ativa.

\section{Considerações finais}

Numa fase de planeamento da estratégia para a educação e formação de um território é fundamental ter presente qual a trajetória de desenvolvimento que o município pretende seguir, pois a relação entre educação e o desenvolvimento afigura-se como estratégica na transformação do território, apresentando uma relação direta com o próprio equacionar da oferta educativa para os diferentes públicos do território.

O exercício levado a cabo pelo município da Lousã vai ao encontro do defendido, encontrando-se este território a desenvolver, em simultâneo, um "Plano Estratégico" e um "Projeto Educativo Local". Neste sentido, julga-se fundamental aliar as políticas de educação às estratégias de desenvolvimento dos territórios, que, sendo diferentes, merecem abordagens diferenciadoras.

O Projeto Educativo Local da Lousã, paralelo à estratégia territorial associada ao Plano Estratégico, deverá ser encarado como uma base para o desenvolvimento de políticas por parte das entidades que dispõem de competência para o efeito, designadamente a autarquia, as escolas, mas também com a sociedade civil, articulando-as com todas as oportunidades de educação formal, não formal e informal, que são proporcionadas por todas as organizações e espaços do território e da vida das pessoas e das comunidades.

Apresentando uma abordagem inovadora, o Projeto Educativo Local da Lousã deverá contribuir para a mobilização da sociedade com o objetivo de formar cidadãos com capacidade para compreender e pensar o mundo global, mas disponíveis para agir de forma autónoma e responsável (por si mesmos e pelos que consigo interagem) no seu mundo local, em resultado de uma leitura crítica da sua realidade. Portanto, ainda que com referenciais e saberes globais, a educação tem que ser, também, pensada a partir dos contextos locais, para que possam ser garantidos os recursos educativos necessários, os espaços de vida suficientemente desafiadores e o acompanhamento a todos os que necessitam de ajuda para dar sentido às suas aprendizagens contínuas, promovendo o seu reconhecimento pessoal e social (Alcoforado, 2014).

\section{Referências}

Albrechts, L. (2006). Shifts in strategic spatial planning? Some evidence from Europe and Australia. Environment and Planning A, 38, 1149-1170.

Albrechts, L. (2010). More of the same is not enough! How could strategic spatial planning be instrumental in dealing with the challenges ahead? Environment and Planning B: Planning and Design, 37, 1115-1127.

Albrechts, L., Healey, P., \& Kunzmann, K. R. (2003). Strategic Spatial Planning and Regional Governance in Europe, Journal of the American Planning Association, 69(2), 113-129.

Alcoforado, J. L. M. (2014). Uma Educação para Todos, ao Longo e em todos os Espaços da Vida: desafios para a construção de políticas públicas promotoras de uma cidadania planetária crítica e ativa. In Marinalva Freire da Silva (Eds.), Mundos Distantes, Diálogos Possíveis: a vida em Mosaico. João Pessoa, Ideia.

Alexandre, J. (2003). O planeamento estratégico como instrumento de desenvolvimento de cidades de média dimensão (Dissertação de mestrado). Universidade de Aveiro, Aveiro. p. 186

Barros, C. \& Gama, R. (2010). Marketing territorial como instrumento de valorização dos espaços rurais: uma aplicação na Rede das Aldeias do Xisto. Cadernos de Geografia, 28/29, 93-106.

Barros, C. (2011). Planeamento Estratégico de Marketing Territorial e perspectivas de desenvolvimento na Região Autónoma da Madeira (Dissertação de mestrado). Faculdade de Letras da Universidade de Coimbra, Coimbra.

Bütüner, H. (2016). Systematic Strategic Planning a Comprehensive Framework for Implementation, Control, and Evaluation. Boca Raton: CRC Press.

Cordeiro, A. M. R. (coord) (2015). Enquadramento demográfico e socioeconómico do Concelho da Lousã, Projeto Educativo Local do Concelho da Lousã, vol.1. Coimbra: Faculdade de Letras da Universidade de Coimbra. Relatório inédito. 
Cordeiro, A. M. R. \& Alcoforado, J. L. M. (coord.) (2015). Programa intermunicipal de prevenção do abandono escolar e promoção da igualdade de acesso ao ensino da comunidade intermunicipal região de Coimbra Contextos territoriais preditores do (in)sucesso escolar - Documento síntese e plano de ação. Coimbra: Faculdade de Letras da Universidade de Coimbra. Relatório inédito.

Cordeiro, A. M. R. (coord.) (2016). Lousã horizonte 2031 Plano Estratégico da Lousã. Relatório técnico. Faculdade de Letras da Universidade de Coimbra, Coimbra. Relatório inédito.

Cordeiro, A. M. R., Alcoforado, L., \& Ferreira, A. G. (2012). Projeto Educativo Local. Um processo associado a estratégias de desenvolvimento integrado e sustentável. Cadernos de Geografia, 30/31, 313-324.

Cordeiro, A. M. R, \& Barros, C. (2011). Uma cidade sustentável, um território coeso: o exemplo da Figueira da Foz. Filosofia de um projeto integrado de planeamento e ordenamento do território. Actas do $17^{\circ}$ Congresso da Associação Portuguesa para o Desenvolvimento Regional (APDR) e 5o Congresso de Gestão e Conservação da Natureza, 1336-1345.

Cremer-Schulte, D. (2014). With or Without You? Strategic Spatial Planning and Territorial Re-Scaling in Grenoble Urban Region. Planning, Practice \& Research, 29(3), 287-301.

Faludi, A. (2010). Cohesion, Coherence, Cooperation: European Spatial Planning Coming of Age? London and New York: Routledge.

Ferreira, A. F. (2005). Gestão estratégica de cidades e regiões. Lisboa: Fundação Calouste Gulbenkian.

Fonseca, F. (2006). O planeamento estratégico em busca de potenciar o território: o caso de Almeida (Dissertação de mestrado). Universidade do Minho, Braga.

Gonçalves, J., \& Ferreira, J. (2015). The planning of strategy: A contribution to the improvement of spatial planning. Land Use Policy, 45, 86-94.
Güell, J. (2000). Planificación Estratégica de Ciudades. Barcelona: Editorial Gustavo Gili, Projecto e Gestion.

Hall, P. (2014). Cities of tomorrow an intellectual History of Urban Planning and Design since 1880. Chichester: Wiley Blackwell.

Hall, P., \& Tewdwr-Jones, M. (2011). Urban and Regional Planning. Oxon: Routledge.

Healey, P. (2004). The Treatment of Space and Place in the New Strategic Spatial Planning in Europe. International Journal of Urban and Regional Research, 28(1), 45-67.

Knowles, R., \& Rozenblat, C. (Editors) (2016). Sir Peter Hall: Pioneer in Regional Planning, Transport and Urban Geography. Springer.

Lake, N. (2012). The Strategic Planning Workbook. London: Kogan Page.

Mendes, J. (2012). O Futuro das Cidades. Coimbra: Edições Minerva.

Neves, A. (1996). Planeamento estratégico e ciclo de vida das grandes cidades: os exemplos de Lisboa e de Barcelona. Oeiras: Celta Editora.

Olesen, K., \& Richardson, T. (2012). Strategic Planning in Transition: Contested Rationalities and Spatial Logics in Twenty-First Century Danish Planning Experiments. European Planning Studies, 20(10), 1689-1706.

Portugal (2013). Lei no 75/2013, de 12 de setembro. Diário da República no 176, Série I de 2013-09-12.

Tomás, P. C. (2005). Património construído e desenvolvimento em áreas de montanha: o exemplo da Serra da Lousã (Dissertação de doutoramento). Faculdade de Letras da Universidade de Coimbra.

Recebido: Nov. 15, 2016

Aprovado: Fev. 03, 2017 